\title{
Transformation of Fan Culture Under the Influence of Social Media
}

\author{
Bolin $\mathrm{Jia}^{1, \mathrm{a}, \uparrow, *}$, Jiaying $\mathrm{Li}^{2, \mathrm{~b}, \dagger}{ }^{, *}$, Jingkun $\mathrm{Ma}^{3, c, \uparrow, *}$ \\ ${ }^{1}$ School of Journalism and Communication, Chongqing University, 401331, Chongqing, China. \\ ${ }^{2}$ Duke Kunshan University, 215316, Suzhou, Jiangsu, China. \\ ${ }^{3}$ School of Interpreting and Translation, Beijing International Studies University, 100024, Beijing, China. \\ *Corresponding author.Email: ${ }^{*} 20181448 @$ cqu.edu.cn, bjiaying.li@dukekunshan.edu.cn,
}

c2018220767@stu.bisu.edu.cn

These authors contributed equally.

\begin{abstract}
Nowadays, fandom and fan culture have step into the eyes of the public gradually. Many people are curious about how this subculture carries weight to society. In this article, we mainly focus on discussing two problems. The first is how the development of social media and technology influences fandom. The second is how the fan culture influence back to the economy and society. For the importance, our study could help with the further study on fan culture, social media, explore their relationship, and help the audience have a better understanding of fandom and fan culture and their working principle under the surface. The method we choose to solve the problem is literature review. Through reviewing journal articles searched from google scholar, China National Knowledge Infrastructure (CNKI), and some secondary data from media reports. And we find that fan culture can be considered participatory culture, which was promoted by the development of social media (development of technology pushes the change of social media). And as the participatory culture grows, fans change their roles and actively influence back society. Our general findings are that emerging new media promote the role change of fans, push the subculture to stand on the stage of mainstream culture, and become a stream that cannot be ignored in the social economy. Our work can be used in entertainment media firms, which helps them have a better acquaintance with their targeted customer and helps the relative department govern the fandom market.
\end{abstract}

Keywords: Social Media, Fan Culture, Participatory Culture, Fan Economy.

\section{INTRODUCTION}

Fans and fandoms have been existing for quite a long time. However, in recent years, their presence seems to have gained more public attention than ever. In 2009, Cai pointed that communication and interaction among fans account for a large proportion of fans' participatory behaviors, which are blocked due to time-space limitation in early years and later empowered by the emergence of the Internet and the rise of social media [1]. With the development of social media, which serves as a convenient platform for fans to interact with their idols and plan and carry out various activities, fans are enlarging the scope and variety of their activities.

In addition, by funding their idols and purchasing products endorsed by their idols, they also create what is usually called the fan economy. Compared with the developed countries, the fan culture in China develops later. In 2012, Chinese scholar Li believed that fan culture has the potential to become a kind of consumer culture [2]. This is particularly the case in the variety show Produce101, a spinoff from the South Korean franchise show Produce 101, where fans spend a large amount of money to vote for their favorite participants so that they could debut when the show ended. On the other hand, fans are not merely consumers. They also take on the role of producers: Many fan productions are emerging on different social media platforms: photo or video editing, fan art, slogan and doll making, fan fiction based on true characters, offline gathering, and so on. These phenomena show that social media facilitate fan's activities and empower fans to a large extent. For these 
reasons, scholars like Shi and Yue regarded the participation of fans as an important driving force for the development of the cultural entertainment industry, and even further, for social democratization and liberalization [3].

However, the greater power of fans is not always a good thing. While affirming the commercial potential of fan culture, Li also called for vigilance to the blindness and fanaticism of fan culture, which should be guided properly [2]. We have seen some fan behaviors violating artists' personal lives or harming other people's interests. For example, the prohibition of access to Archive of Our Own (AO3) mirror site in China due to the improper report from a fan. Some fans who are too protective of their idols even will not accept any criticism, which often leads to conflicts or an ill climate where people cannot voice their opinions. Given these circumstances, the social impact of the present fan culture stands as a topic worth looking into.

By analyzing how fans have a greater say than the past and the overall situation in fan culture nowadays, we hope to demonstrate the powerful influence of fan culture fueled by social media. We would also look into the impacts of the increase of power in fans and give some reasonable suggestions on how we can guide it towards a path beneficial to the society. Our findings could also provide references for researchers and policymakers working on managing social media and fan culture.

The article will be divided into three sections. In the first section, we will analyze the development of social media in the past decade. Then we will move on to the second section, where we will elaborate on how the role of fans has changed during these years. Finally, in the third section, we will look into the influence of fan culture in terms of social impact and economic impact.

\section{METHOD}

In this study, literature review is the main research method. We use this method to gather information about social media and fan culture. In the literature we gathered, English literature and Chinese literature were selected from Google Scholar and China National Knowledge Infrastructure (CNKI) respectively. Other secondary data sources will come from media reports.

\section{FAN CULTURE IN THE WAVE OF SOCIAL MEDIA}

Fan culture has been around for centuries. However, it is the emergence of social media in recent decades that has led to the remarkable transformation and development of fan culture. Most obviously, fans play a more active role. They are not like completely passive receivers in the past but participate in the production process of cultural products on their own initiative. All these phenomena show that fan culture profoundly impacts the economy, culture, society, and other fields.

\subsection{Social Media and the Development of Fan Culture}

In this section, we would like to discuss the relationship between social media and fan culture.

\subsubsection{The Impacts of Digital Networks}

Many processes, such as forming fan groups and creating fan culture, require communication and interaction. However, due to the limited means of communication, in the pre-Internet era, communication between fans was always hindered in various ways, either by long distances or inconvenient schedules. Henry Jenkins argues that the emergence of digital networks has made it possible for fans who might not otherwise have met to have meaningful conversations and has created a new context that fans can share [4]. It is reasonable to declare that those barriers mentioned above have been broken in a digital network environment where the degree of fan interaction is much higher than in the preInternet era, as is the degree of fan culture development.

\subsubsection{The Interaction between Social Media and Fan Engagement}

In the first 10 years of the new century, the world Internet gradually developed from Web1.0 to Web2.0. Compared with Web 1.0, Web 2.0 emphasizes more on interactivity. This feature has laid the foundation for the emergence of social media platforms and thus promoted the new development of fan culture. Shuojia Guo points that the rise of social media has greatly broadened the scale of fan groups and promoted the communication within fan groups. Because the fans can communicate and discuss on social media in real time, which all result in the prosperity of the immediacy and participation of the current fan culture [5].

In the second decade of the 21 st century, fan culture has seen a new boom around the world, which is related to the continuous upgrading of social media. All the efforts that social media make to increase users' stickiness and activity objectively help fan culture grow. Take Weibo for example, China's largest entertainment social media platform. When a user chooses to follow a celebrity, the user is immediately notified of the celebrity's tag, channel, and fan group. Further, through big data technology, the user will be frequently recommended the content related to or similar to the celebrity, including entertainment news, commercial advertisements, and other content, when browsing information 


\subsubsection{Celebrities' Active Participation in Social Media}

Moreover, the growth of fan culture is not the result of the rise of social media alone. Celebrities also choose to use social media to enhance the sense of intimacy and provide greater possibilities for interaction [5]. In other words, it's not just fans who are discovering the power of social media. Celebrities and the business communities behind them are also noticing the value that social media can bring. Since she joined Twitter in 2008, Lady Gaga has insisted on interacting with her fans as a publicity hot spot. Lucy Bennett has summarized this kind of phenomena as "the emergence and widespread use of social media by celebrities are trying to reconfigure the contact level and participation depth between both fans and celebrities"[6]. Since its establishment in 2009, Weibo has also attracted a large number of celebrities to come here to share their daily life and communicate with their fans, which attracts more fans and improves their business value. With the expansion of fans, fan culture and fan economy have entered the mainstream of society.

\subsubsection{Brief Summary}

The growth of fan culture results from a multi-faceted effort by social media, fans, and celebrities. The emergence and development of social media have narrowed the distance between celebrities and fans, creating a new environment for real-time comments and feedback from fans. At the same time, the development of fan culture has promoted the development of the fan economy. Under the background of the double prosperity of fan culture and fan economy, fans have become an indispensable group in the social scene, and their influence soared.

\subsection{The Role Change of Fans}

We also want to discuss the role change of fans these years. We consider that the change can be detected in two aspects: passive to active and receiver to producer. Meanwhile, these changes were deeply affected by the development of the Internet and social media, especially the change from traditional media (television, radio, print advertisements, and billboards) to emerging we media (a global innovation agency, publisher, studio, and incubator for networked knowledge and culture, which focuses on normal people as the audience, communicators, and users).

\subsubsection{From Receiver to Producer}

Firstly, the exchange of traditional media to emerging social media promotes the development of the participatory culture of fandom, which makes their role change from the receiver to the producer. According to Henry Jenkins, participatory culture is a notion to describe how media fandom operates, and it is known as spectator culture [7]. And we consider participatory culture is important to fan culture because fandom was participatory in so far as fans formed alternative interpretations that were often expressed through unauthorized cultural productions. Before the 2010s, the mainstream media was still traditional media, making the fans only receive information from official sites, and there is not enough space or suitable platform for fandom to expand. However, John Fiske pointed out that fans are the producers and consumers of popular culture capital, and fan culture has two cores, chatting and derivative creation [8]. Under the control of traditional media, although fans in that time do not have enough space to communicate with each other, there are still platform like Tieba (in 2009, the Tieba of Yuchun Li has already had over billion) for them to exchange commands and show their derivative creative productions. Therefore, after 10 years, we media emerged, newly developed platforms like Weibo, Bilibili, the developed technology promote the progress of the social media revolution, producing more alternative space for fandom and participatory culture to grow. According to Qi Cai, fans are always the first user and promoter of new media techniques, and the most direct driver of a true communications revolution is, as always, technology [1]. In the generation of we media, fans have taken the best advantage of social media platforms to promote their fandom. The place like Chaohua (community of Weibo) is now a community for fans to exchange the dynamics of the idol, communicate feelings, and produce artworks. Along with the revolution of social media these years, the role of fans is not only receiver and consumer of information, but also producer and participants of derivative creations.

\subsubsection{From Passive to Active}

From another angle to consider this question, we could also say that the revolution of social media also changes the mindset of fans from passive to active. As we said above, the essence of fan culture is participatory culture. Fans need to have communication in the fandom. The change of mindset can be considered a willingness to communicate with other people and enlarge their fandom. According to Qi Cai and Yaoying Huang, based on the technology development, from traditional media to emerging we media, information spreading is also changed from node to surface to multiple nodes exchange [9]. In the age of traditional media, the role of fans on the internet is more like the audience. They receive information from media and form concepts but lacks the platform for expression and comments. People can only communicate their ideas with their surroundings which is very limited under the condition of traditional media, and it is also hard for them to form a circle share a common hobby. While under the condition of we media, people can send out their fragment information through the Internet to everyone and receive the information they are 
interested in immediately. Fans in this generation can make use of these conditions and form their fandom quickly. Like in Douban, you can choose to join different groups and find a few people with commons, which stimulate the willingness of expression quite a lot. Therefore, we conclude that social media revolution encourages expression and different voices, which makes fans braver to share their ideas, and the mindset change from passive to active.

\subsection{Fan Culture's Influence upon Our Society}

Thanks to social media, fans have gained so much power compared to the past. As an integral part of society, being such a powerful group allows them to have a strong influence that cannot be neglected on our society. The influence is multi-dimensional and impressive.

\subsubsection{Economic Influence: Fan Economy}

Among the most followed celebrities on Weibo, $\mathrm{Na}$ Xie, who ranked first, has 127 million followers, and He Chen, who ranked the 20th, has 69.26 million followers. The figure shows how enormous the fan base is in China, which is also targeted by companies as their potential market. In his 1992 book Textual Poachers, Jenkins described fandom as a base for consumer activism among five core dimensions [7]. Indeed, many product producers seek the endorsement of famous actors or singers to boost sales. Combining a celebrity's advertising post on his or her social media and other forms of advertisement is now considered a reliable marketing strategy by big companies.

Fans' purchase power is also demonstrated when their object of admiration makes a new production, whether it is music, a film or other forms of achievement. For example, when a singer or a band releases a new album, fan bases will immediately devote themselves to negotiation with the publisher to get the lowest price possible and design special merchandises like slogans, canvas bags, bottles, etc. These merchandises, with beautiful pictures of the singer or band on them, must be purchased with the album, which serves to attract as many fans as possible to purchase the album. Baidu Jeon Jungkook Bar, a fan base for the K-pop sensation BTS' member Jungkook, purchased a total of 166,200 Map of the Soul: Persona albums after its release. As Li put it, when fans' need is met and they are excited about what will come next, they will be willing to spend more money; when the consumption is interactive, it lasts longer [2].

\subsubsection{Cultural Influence: Creation Boom and Values Shift}

Recent years have witnessed a boom of fan productions: fan fiction, fan videos, fan arts, fan edits, etc. Jenkins believed that the reason why more and more people are participating in this creation is because the network provides them with a safe place where they can experiment with new passions or activities [4]. The massive online community offers fans with the audience no matter their creation is good or bad. Many fans with specialties in a particular area even give instructions to rookies by using social media or making instruction videos. Through social media, each fan could find their way to participate in content creation and feel a sense of belonging and achievement.

The advent of social media has also enabled people to voice their opinions in an unimpeded way. Information and knowledge could no longer be cut off from the public; public opinion is free from control and manipulation. Thus, independent of the traditional media, fans have come together to break the mould of society. Their strong voice, in turn, exerts influence on traditional media [1]. Fans question the values held by most people, for example, the definition of beauty.

Ju Wang, a participant in one of the most popular variety shows in China, Produce 101, has dark skin and a strong body contrary to the typical appearance of female idols who are usually slim with light skin color. At the beginning of the show, netizens criticized her harshly, making memes making fun of her skin and exaggerated expressions. However, as the show went on, $\mathrm{Ju}$ Wang expressed her respect for the independence of females and demonstrated her candid and ambitious personality, which gained her a lot of fans, many of whom were against her before. Her fans did their utmost to promote her and vote for her, contributing to her rising popularity. People began to recognize this different definition of beauty. Global Times wrote: "The personality Wang displays coincides with the shifting attitudes of China's younger generations [10].'

\subsubsection{Social Influence: Public Welfare}

As mentioned before, China has a large fan base, which can play an important role in donation and relief. Fans can deliver what they appeal for online [1]. Many fan bases continue to make donations to international and domestic organizations such as Whale and Dolphin Conservation, WWF and participate in various projects to help advance the cause of animal, environmental protection, and human welfare.

After the coronavirus outbreak in Wuhan at the end of 2019, many fan bases and organizations in China rallied to raise funds for the epicenter of the epidemic. By February 2020, there were more than 300 fan groups in the joint force that has obtained face masks, protective gowns, and other crucial supplies to donate to medical practitioners fighting in Wuhan. Among the deeply concerned fan groups, Lun Deng's fan club stood out. More than 3000 members of Deng, a famous actor with 
more than 39 million followers on Weibo, contributed to the donation effort by raising more than 230,000 yuan $(\$ 32,752)$ in 12 hours [11]. By doing their utmost to support Wuhan, fans show care and compassion for their compatriots and a sense of social responsibility.

\section{CONCLUSION}

In the introduction above, we mentioned that we hope to discuss the transformation and development of fan culture driven by social media and explore the strong influence of fan culture in business, culture, and society. However, our previous ideas may be one-sided. For example, our views on the commercial impact of fan culture may be too positive, while our views on the social impact of fan culture may be relatively pessimistic. In fact, the influences of fan culture are both good and bad.

The natures of social media, real-time and interactive, create a free communication environment for fans that is not limited by time and distance. The feature of social media, multimedia, also provides more diversified forms of expression for fans' communication. Social media also use new technologies such as big data to innovate the way of information push and enhance user engagement, all of which contribute to the development of fan culture. The involvement of celebrities and commercial capital allows social media and fan culture to grow faster. In the meantime, the fan economy is also thriving.

The revolution of social media promotes the development of participatory culture. The tendency of social media to get more open to the public and have more people joined in will strengthen the speaking authority of fans since they will have more and more platforms to express their feelings, communicate with others, and make productions for their idols. Along with the activeness and passion of produce growing, the fandom is also increasing its field. The power of the subculture is getting stronger, and it is a huge shock to the mainstream culture. Stand in the practical view. The whole society will receive more information and hear more voices from fandom. Once it is accepted and accustomed by the public, it may become a part of the mainstream culture.

Social media serves as a platform for fan culture, which exerts influence on different aspects of our lives. Fan culture's economic influence is mainly demonstrated by the fan economy, gaining stronger momentum in recent years. In terms of cultural influence, fan culture encourages fans to create content by providing them with the audience and to hold values different from the majority of society by letting their voices be shared and heard. In addition, with respect to its social influence, fan culture also acts as an important contributor to public welfare, attributable to its strength in numbers and sense of social security.
The role change of fans indicates a shift in the relationship between fans and their idols, which should be taken into account by agencies when forming business strategies to better promote their celebrities. At the same time, the psychological cause behind the role shift of fans is worth further research and discussion. Meanwhile, with fans actively engaging in fan production, some excellent content producers even make money by their creations, which leads to the controversy of the legitimacy of such behaviors. Some believe that it violates the original producer's copyright or intellectual property right. The legal status of some fan productions stays unclear, which calls for more concern and effort.

Moreover, as fans' influence on our society is becoming stronger and stronger, some problems begin to emerge. For example, a recent variety show, Youth with You Season 3, was suspended by the Beijing Municipal Radio and Television Bureau. The mechanism of the show encouraged viewers to purchase Mengniu brand (the biggest sponsor of the show) milk so that the viewers can scan the QR codes inside the caps of the milk bottle to vote for their favorite trainees who compete in the show to become idols. Many viewers, especially the young, bought large amounts of milk that they cannot drink off and just poured them into sewers after scanning the code, which was criticized harshly by netizens and society as wasting food when the country is striving to save food. This scandal should remind the government of the necessity to introduce appropriate regulations on the entertainment sector as more and more fans are engaged in the entertainment industry, and some legal and regulatory gaps need to be filled. At the same time, the operators and managers in the media and entertainment industry should always bear professional ethics and social responsibility in mind, instead of regarding fans as nothing but a tool for making money. Indeed, social media has empowered fans and fan culture significantly. However, such a strong force needs to be guided properly towards a beneficial role to the society.

\section{REFERENCES}

[1] Q. Cai, The Internet and the Development of Fan Culture, in: X. Liu, J. Chen, Y. Wang (Eds.), Chinese Journal of Journalism \& Communication, Renmin University of China, Beijing, 2009 (7), pp. 86-90.

[2] L. Li, Fan culture under consumerism, in: C. Jing (Eds), Youth Journalist, Dazhong Press Group, Jinan, 2012 (14), pp. 25-26. DOI: https://doi.org/10.15997/j.cnki.qnjz.2012.14.009

[3] Y. Shi, G. Yue, Participatory Culture in the Digital Age -- Take the Audiences' Creation about Star Wars on the Internet for Example, in: Y. Luo, Z. Qin (Eds.), Journalism \& Communication Review, 
Wuhan Publishing House, Wuhan, 2009, pp. 129134.

[4] H. Jenkins, Fandom, negotiation, and participatory culture, in: P. Booth (Eds.), A companion to media fandom and fan studies, John Wiley \& Sons, Inc., Oxford, 2018, pp. 11-26. DOI: https://doi.org/10.1002/9781119237211

[5] S. Guo, Charging Fandom in the Digital Age: The Rise of Social Media, in: C. Wang (Eds.), Exploring the Rise of Fandom in Contemporary Consumer Culture, IGI Global, Hershey, 2018, pp. 147-162. DOI: https://doi.org/10.4018/978-1-5225-3220-0

[6] L. Bennett, Fan/celebrity interactions and social media: Connectivity and engagement in Lady Gaga fandom, in: L. Duits, K. Zwaan, S. Reijnders (Eds.), The Ashgate Research Companion to Fan Cultures, Ashgate Publishing, Ltd., London, 2014, pp. 109120. DOI: https://doi.org/10.4324/9781315612959

[7] H. Jenkins, Textual Poachers: Television Fans and Participatory Culture, Routledge, New York, 1992. DOI: https://doi.org/10.4324/9780203361917

[8] J. Fiske, The Cultural Economy of Fandom, in: L.A. Lewis (Eds.), The Adoring Audience: Fan Culture and Popular Media, Routledge, London, 1992, pp. 30-49.

DOI: https://doi.org/10.4324/9780203181539

[9] Q. Cai, Y. Huang, New Media Communication and the Development of Audiences' Participatory Culture, in: P. Liu, Q. Wang (Eds.), Shanghai Journalism Review, Shanghai United Media Group, Shanghai, 2011 (8), pp. 28-33. DOI: https://doi.org/10.16057/j.cnki.31-

$1171 / \mathrm{g} 2.2011 .08 .009$

[10] Y. Zhang, 2018, Woman not slim and fair shoots to phenomenal stardom with LGBT, feminist fan base, [Online] Retrieved May, 25, 2021, from https://www.globaltimes.cn/page/201806/1105683. shtml

[11] N. Chen, 2020, Pop fans rally to raise funds for Wuhan, [Online] Retrieved May, 20, 2021, from http://www.chinadaily.com.cn/a/202002/05/WS5e3 a1ecca310128217274fd2_6.html 